\section{SCIENTIFIC STUDY OF SOCIETY}

\author{
BY DR. HENRY A. MESS
}

Bedford College for Women, London

\section{The Natural Sciences and the Social Sciences}

THE lengthy correspondence in The Times a few months ago, a number of articles and letters in NATURE, and the discussions at one or two conferences, all bear witness to the widespread interest in the scientific study of society. They also show a certain amount of confusion of thought and some lack of information as to what is actually being done.

It is natural that there should be this interest at the present time. We have all learned some bitter lessons in the last few years. Among other things we have discovered what great disasters can come upon mankind through science. It was stated recently that one of the first men to fly, an old man now, is heartbroken by the knowledge of what flying has actually come to be. Nobel, who developed the manufacture of high explosives, was similarly saddened by the use to which they were put.

But we cannot turn our backs on science. Nor is it the development of science which is the real evil; it is the lop-sided development of science. It is the rapid growth of the natural sciences without a corresponding growth of the social sciences which has brought such dangers and disasters on us. This is now generally recognized, not least by the natural scientists.

The contrast between the competence of men in some directions and their incompetence in other directions has become a commonplace. Men can mould matter and use physical forces with remarkable facility. They have made the fairy tales come true; they can fly in the air, they can travel under the sea, they can penetrate the recesses of mountains, their whispers can be heard across continents and across oceans; they can work wonders with living matter, they can bring into existence new plants and new breeds of animals. Yet with all these powers at human command, there are millions who are imperfectly nourished, millions who are badly housed. Wars persist, more horrible because of our science. In the intervals between wars there is social strife; and we have the bitter paradox that when our manufacturers and our farmers produce abundantly, they are in danger of being ruined by low prices. Recurrent periods of unemployment blight the lives of multitudes. All this we seem to be unable to prevent.

The contrast between achievement and futility is glaring; and it is a challenge. What response to it shall we make? The answer is obvious. Since we cannot turn our backs on science, even if we would, we have no option but to go forward, to apply science to those spheres of human life in which at present we are so incompetent. Inevitably the question is being asked, more and more insistently, whether the application of scientific methods to the study of society cannot give us a control over social processes comparable to our control over physical forces. Can we find a remedy for the evils, of which we are so sensible, in a scientific study of society?

The answer is being given quite rightly that we can; a great increase of knowledge and a great increase of control are certainly possible. But having said that, it is necessary to give a warning. To argue directly from what the natural sciences have done to what the social sciences might do is unsound. The social sciences are bound to be very different from the natural sciences. Their subject-matter is different. The chemist and the physicist have to do with inanimate things, which do not have moods and wills, which do not alter just because they are being examined. The social scientist is dealing with nothing so consistent, nothing so tractable; he is dealing with the relations of human beings, conscious, sensitive, wilful, living creatures. If anyone thinks that we are likely to obtain laws of social development as precise and as little subject to variation as the great physical laws, he will pretty certainly be disappointed. It has hindered, and not helped, the social sciences that some of their practitioners have made exaggerated claims on their behalf. What can be claimed fairly is that the social sciences are capable of helping us to a much better understanding of the present and to a much clearer perception of the possibilities, the impossibilities and the probabilities of the future.

It cannot be said too emphatically that we need to be clear in our minds as to the distinctive natures and roles of the physical sciences and the social sciences. The former can contribute much to human welfare, as also much to human unhappiness; we need to think hard how to make the best of their contribution, and to do so will call for co-operation between physical scientists and social scientists. In this the former have a big part to play. But they cannot help much in what is one of the most urgent tasks of men to-day, the analysis of the nature and functioning of societies with a view to increasing our control over social forces. The physical scientists and the social scientists have really very little in common. Of course, they must both be objective, and they must both follow the rules of logic. But that is about all they have in common. Only harm is done if any attempt is made to force the methods or the canons of one upon the other. The chemist can experiment and weigh, and he can hope for exact results. There is only a very restricted field for experiment in the social sciences, and the social scientist is bound to take into account much that cannot be measured, but can only be assessed: hopes and fears, prejudices, the force of custom, the power of ideas. Some grotesque results have been reached when attempts have been made to measure that which is not really amenable to measurement; and, let us repeat, findings must often be stated in terms of alternatives and of probabilities. For example, I think that the majority of competent students of local government in Great Britain would say that either local government areas will be revised and enlarged or local authorities will decline in power relatively to the central government departments. Again, there is a strong likelihood that a defeated nation will develop within a decade or two a harsh and aggressive nationalism; but alternatively it may fall into a state of apathy and accept a position of permanent inferiority ; or, more rarely, it may bend its energies to finding an idealistic solution of its difficulties, as Denmark did after 1864. It is impossible to say for certain which of these will happen, but it is very likely that one of them will happen.

The case is rather different with regard to the biological sciences. But here also we need to distinguish between the utilization of their findings for the advancement of human welfare and the more specialized task of analysing society. As an example of the former, we may take the impact upon public opinion of the researches of the dieticians. Clearly we are in deep debt to them, and clearly to maximize 
the utilization of their work there must be cooperation between physiologists and social scientists. In the same way there is a good deal of psychological knowledge which can be used. So far there is a parallel with the utilization of the work of the physical scientists. But in addition, the biologist and the psychologist have their distinctive contributions to make to social analysis. The biologists can tell us a good deal about the inheritance of intellectual ability, about the effects of marriages between persons of different race, and so on. The psychologists have taught us a great deal about the workings of the human mind, about the way in which the emotions can distort reasoning; we have such topical studies as Prof. F. C. Bartlett's examination of propaganda ${ }^{1}$.

But while biologist and psychologist, and let us add economist, can throw a good deal of light on the functioning of society, and while each of them can do what no unqualified person can do, yet we should be still far short of an adequate analysis of society. In isolation the various social scientists are liable to fall into serious error, as the literature of eugenics and the long-drawn-out controversy with regard to instincts in man abundantly testify. A correct and an adequate analysis of society cannot be made by biologists only, or by psychologists only, or by economists only. There can only be an accurate and an adequate study of society when the different social sciences are related, and when there is team. work between those who practise them. This has always been a first principle of sociology, which is the general study of society.

The scope and methods of sociology are so commonly misunderstood in Great Britain that it is well to elaborate this a little. Comte's doctrine of the "social consensus" needs modification and re-statement; there are more partial autonomies in the social structure than he realized. Yet that there is an interplay of the various parts can scarcely be doubted, nor that it is intricate and important and needs careful study. Such study is undertaken by the sociologist; and because he is always aware of the interdependence of parts, he views society holistically. The objection generally raised is that the sociologist is attempting too much, and that he trespasses on too many fields. If the sociologist attempted to do the work of the biologist, the psychologist or the economist, that objection would be justified. But it is not so. The sociologist accepts the findings of the specialists; his business is to relate those findings, and to use them in the interpretation of the society which he perceives as a whole ; sometimes also it is his business to make the specialists aware of alternative explanations of social phenomena. Doubtless to do this he requires some elementary knowledge of a number of social sciences, but that is very different to claiming to be an expert in them. It is probably desirable that a sociologist should be really well equipped in at least one specialist social science. That is one of the ways of advance; another is to secure that an increasing number of specialists in one or other of the social sciences have a background of general sociology.

It should be added that the sociologist has also one or two specialisms of his own, parts of the field of social study which have not been annexed by any special social science. Of these specialisms quite the most important is the study of social institutions. Such a book as Westermarck's "History of Human Marriage" falls within this field.

"Political Propaganda", by F. C. Bartlett.

\section{Practical Applications}

When we are considering what practical benefits the scientific study of society might confer upon mankind, it is useful to distinguish between shortrange and long-range inquiries. By short-range inquiries I mean those which are concerned with the problems of a particular society in a particular age. For example, the evacuation of school-children during the present War has presented what I should call short-range problems; the distresses of the Special Areas a few years ago were short-range problems, the many difficulties which arose in connexion with rehousing were short-range problems. The long-range problems are those concerned with social phenomena which are to be found everywhere and always, with such difficult questions as the limits within which human nature can be altered, or the causes of the rise and fall of civilizations.

Now with regard to short-range problems a great deal of advance could be made very quickly. It is largely a question of money; and if more adequate provision is made for the social sciences we can soon produce and employ men and women who will throw a great deal of light on our social problems, and who will ease greatly the process of dealing with them. It would not be difficult to draw up a list of shortrange problems which could be investigated very profitably. Here, for example, are three suitable subjects for inquiry: (1) the difficulties and the effects of migration within Great Britain; (2) the conditions favourable and unfavourable to the growth of civic consciousness and local patriotism; (3) the social life of various types of English towns. On all these subjects something has been done, but not enough. There is much scattered material on internal migration in Government publications and in books dealing with unemployment and the location of industry; there is an interesting unpublished study of assimilation in the East Kent coal-field; but it cannot be said that there has been any adequate sociological study of this social phenomenon which is as interesting as it is important. With regard to the conditions affecting civic consciousness a great deal can be learned from the experiences of the new housing estates, as Mrs. Durant's fascinating study of the growth of Watling has shown us ; her investigation might have been multiplied many times with great advantage. As to studies of particular towns, it is lamentable that we have not as yet any study of an English town which can be set alongside R. S. and H. M. Lynd's "Middletown" and "Middletown in Transition".

Such studies are not mere academic exercises; they supply knowledge much of which could be put to immediate use. Sociologists are in a position to render useful service to Government departments and to local authorities. After the War we shall be building a good many more new estates. A sociologist could point out ways of shortening the process by which a mere collection of houses and of families becomes a true society. In the same way, there is bound to be fresh migration, and a sociologist could suggest ways of easing the strains which there are sure to be when men and women go to live among strangers. I venture to prophesy that the quality of social life in our smaller provincial towns is likely to be in the near future a matter of public concern; here again the sociologists can be of use, though they will be handicapped for lack of those preliminary studies which might have helped them. 
Much assistance could also be given in the sphere of international relations. Prof. C. E. Merriam, of the University of Chicago, with a team of co-workers, has reviewed the methods adopted in various countries to inculcate patriotism. Quite a deal could be learned from those studies which could be applied to the task of creating as quickly as possible a strong loyalty to a reconstructed League of Nations or whatever other supra-national body there may be set up after this War.

The long-range problems are another matter. With regard to these, the number of men and women who are competent to do effective research is likely to be small, and progress is likely to be slow. But sustained research might in time yield results of quite incalculable value. For example, how little we really know at present about human nature, about its variations, how far it is capable of change, to what extent it is the same always and everywhere. Yet there is a vast amount of material existent in the writings of historians and of anthropologists which, if it were carefully examined, might yield valuable results.

Here let me digress to emphasize the very special case which can be made out for generous support of anthropological research. I am not an anthropologist, but, like all sociologists, I am deeply in the debt of the anthropologists. Their special claim derives from urgency; the material upon which they work, the simpler societies, is fast vanishing; investigations which are not made in the next few decades will probably not be made at all; and these investigations throw light on social structure and on human nature which we are scarcely likely to obtain from any other source.

It is, I think, almost essential for effective study of long-range problems, and for that matter it is often desirable for the study of short-range problems, that there should be team-work. A society is a whole, and it needs to be studied as a whole; and that means either the co-operation of many specialists or the work of a man of encyclopædic knowledge. Men of the latter type are rare, are perhaps likely to become rarer. It is to team-work therefore that we must look more and more. But the planning of work by a team, and the intelligent co-operation of teamworkers, both demand that knowledge of the interplay of the different factors in social life which is the special subject-matter of sociology. Everyone praises his own leather, and I do so unashamedly; it seems to me deplorable that the persons in Great Britain who have been appointed specifically to teach sociology can be counted on the fingers of one hand.

Whether that be accepted or not, there is at least widespread agreement that we need to take more seriously the scientific study of society. Concretely, that means better provision in the universities, more chairs and and more lectureships, more post-graduate studentships. It means better utilization of the already considerable knowledge of social scientists, and an enlargement among other things of the number of careers open to them. It means better understanding and more team-work among them. There is also a great work of popular education to be done. We need to increase immensely the number of those who have some scientific knowledge of the nature and functioning of society. When such knowledge is greater, and when it is more widely spread, we shall be on our way to a considerable measure of control of social forces; and we shall increase the use and decrease the abuse of the abundant knowledge placed at the disposal of mankind by the natural scientists.

\section{WEST INDIAN AGRICULTURE \\ BY SIR GEOFFREY EVANS, C.I.E. Royal Botanic Gardens, Kew}

$\mathrm{W}^{\mathrm{s}}$ EST Indian affairs attracted considerable public attention in the period immediately prior to the outbreak of the present hostilities. Severe economic depression and the deplorably low standard of living had indicated that all was not well and. general concern was manifested by the Imperial Government. Signs of considerable distress and labour unrest, culminating in disturbances in various Colonies during the late thirties, resulted in the appointment of a West Indian Royal Commission which toured the various Colonies in the Caribbean area during 1938-39, with the object of making specific recommendations. Unfortunately, the report of this Commission has not yet been released, but the main conclusions reached and certain recommendations made were published in February 1940 (Cmd. 6174). Now apart from Trinidad, which has a big petroleum industry, and British Guiana, which has developed bauxite mining and to a less extent gold and diamond diggings, all these Colonies depend entirely on the agricultural industry for their prosperity. The recorded opinion of the 1938-39 Royal Commission that "agriculture is the principal source of sustenance and wealth in the West Indies and the standards of life must largely depend on the intensive use of the soil" therefore accurately portrays conditions.

It is obvious from this that the betterment of agricultural practice underlies the whole problem of social and material progress in this area. The problems involved are intricate and not easy to solve, and it is opportune, therefore, that H.M. Stationery Office should have been able, even in these difficult times, to publish a book entitled "Agriculture in the West Indies" (Colonial No. 182), which gives a very complete and up-to-date description of conditions as they were just prior to the commencement of this War. The book has been compiled by Dr. H. A. Tempany, agricultural adviser to the Secretary of State for the Colonies, from documents supplied to the West Indian Royal Commission, and from other sources. It forms a valuable record of agricultural conditions in each Colony at the present time besides giving historical data which undoubtedly have considerable bearing on the existing state of affairs.

Unlike most other tropical areas, the West Indies have had no tradition of native agricultural practice to build upon, for the native Indian tribes rapidly disappeared under the Spanish rule which was established at the end of the fifteenth century, and the labour required for development was afterwards met by the importation of Africans and later, after the abolition of slavery, by indentured labour from India and to a lesser extent from China and the Portuguese Atlantic Islands.

As is pointed out in the book referred to above, the system of agriculture is really based on the methods in vogue in Great Britain and the European Continent before the great renaissance of the eighteenth century, with its development of rotations and mixed farming, took place. The negro brought few ideas with him, but perhaps insufficient credit has been given to the changes that have been introduced by the immigrants of East Indian origin. For example, it is perhaps not too much to say, that without the help of their traditional art, the development of the rice industry, which shows considerable 